\title{
GlyT-I Inhibition Attenuates Attentional But Not Learning or Motivational Deficits of the Sp4 Hypomorphic Mouse Model Relevant to Psychiatric Disorders
}

\author{
Jared W Young, ${ }^{*, 2}$, Mary E Kamenski ', Kerin K Higa', Gregory A Light ${ }^{1,2}$, Mark A Geyer ${ }^{1,2}$ and Xianjin Zhou ${ }^{1,2}$ \\ 'Department of Psychiatry, University of California, San Diego, La Jolla, CA, USA; ${ }^{2}$ Research Service, VA San Diego Healthcare System, San Diego, \\ CA, USA
}

\begin{abstract}
Serious mental illness occurs in $25 \%$ of the general population, with many disorders being neurodevelopmental, lifelong, and debilitating. The wide variation and overlap in symptoms across disorders increases the difficulty of research and treatment development. The NIMH Research Domain of Criteria initiative aims to improve our understanding of the molecular and behavioral consequences of specific neurodevelopmental mechanisms across disorders, enabling targeted treatment development. The transcription factor Specificity Protein 4 (SP4) is important for neurodevelopment and is genetically associated with both schizophrenia and bipolar disorder. Reduced Sp4 expression in mice (hypomorphic) reproduces several characteristics of psychiatric disorders. We further tested the utility of Sp4 hypomorphic mice as a model organism relevant to psychiatric disorders by assessing cognitive control plus effort and decision-making aspects of approach motivation using cross-species-relevant tests. Sp4 hypomorphic mice exhibited impaired attention as measured by the 5-Choice Continuous Performance Test, an effect that was attenuated by glycine type-I transporter (GlyT-I) inhibition. Hypomorphic mice also exhibited reduced motivation to work for a reward and impaired probabilistic learning. These deficits may stem from affected anticipatory reward, analogous to anhedonia in patients with schizophrenia and other psychiatric disorders. Neither positive valence deficit was attenuated by GlyT-I treatment, suggesting that these and the attentional deficits stem from different underlying mechanisms. Given the association of SP4 gene with schizophrenia and bipolar disorder, the present studies provide support that personalized GlyT-I inhibition may treat attentional deficits in neuropsychiatric patients with low SP4 levels.
\end{abstract}

Neuropsychopharmacology (20I5) 40, 27I5-2726; doi:I 0.I038/npp.20I5.120; published online 27 May 2015

\section{INTRODUCTION}

Mental health disorders affect approximately one-quarter of the world's population and are commonly lifelong and debilitating. The sufferers of such disorders exhibit a myriad of distinct yet overlapping symptoms. This overlap is consistent with evidence that many illnesses share numerous associated genetic polymorphisms. Recognizing these overlapping genes and symptoms, the National Institutes of Mental Health began the Research Domain Criteria (RDoC) initiative to provide a new way of classifying psychopathology based on dimensions of functioning (Cuthbert, 2014). By investigating genetic constructs associated with numerous psychiatric disorders-particularly those relevant to neurodevelopment (Insel and Wang, 2010)-and testing behavioral domains affected across those disorders, more circuit-specific targeted treatments may be developed.

\footnotetext{
*Correspondence: Dr JW Young, Department of Psychiatry, University of California, San Diego, 9500 Gilman Drive MC 0804, La Jolla, CA 92093-0804, USA, Tel: + I 619543 3582, Fax: + 6197359205 , E-mail: jaredyoung@ucsd.edu

Received 14 December 2014; revised 12 February 2015; accepted 13 February 2015; accepted article preview online 24 April 2015
}

Specificity protein 4 (SP4) gene is a member of the SP1 family of transcription factors and is important for neurodevelopment. The SP4 gene recognizes GC-rich sequences of 'CpG islands' around the promoters of a variety of genes and is neuronally localized (Supp et al, 1996; Zhou et al, 2005). SP4 is therefore highly expressed during neuronal differentiation (Sun et al, 2014; Zhou et al, 2007), and regulates dendritic patterning and neural development during maturation (Ramos et al, 2007; Zhou et al, 2007). Importantly, the SP4 gene was deleted in some patients with schizophrenia (Tam et al, 2010; Zhou et al, 2010), whereas single-nucleotide polymorphisms of SP4 have also been associated with schizophrenia (Zhou et al, 2009), bipolar disorder, and major depressive disorder (Pinacho et al, 2011; Shi et al, 2011; Zhou et al, 2009). Such associations are likely functionally significant given that SP4 protein levels are reduced in peripheral blood mononuclear cells in first-episode schizophrenia patients (Fuste et al, 2013). Reducing Sp4 expression (hypomorphic (Hyp)) in mice results in abnormalities relevant to schizophrenia and bipolar patients, eg, reduced sensorimotor gating (Zhou et al, 2005) and reduced $\mathrm{N}$-methyl-D-aspartate receptor (NMDAR) protein expression (Zhou et al, 2010). These mice are also hypersensitive to the 
NMDAR noncompetitive antagonist ketamine and competitive NMDAR antagonist SDZ 220-581, resulting in reduced habituation to a novel environment (Ji et al, 2013). Interestingly, acutely ill schizophrenia patients exhibit reduced habituation to a novel environment (Perry et al, 2009). Moreover, patients with schizophrenia are hypersensitive to phencyclidine (Luby et al, 1959), another NMDAR antagonist. Hence, Sp4 Hyp mice-that are genetically relevant to psychiatric patients-recreate some behavioral abnormalities seen in such patients.

The behavior of Sp4 Hyp mice has yet to be assessed in cross-species cognitive/behavioral paradigms that are $\mathrm{RDoC}$ relevant however (tasks such as those reviewed in Young and Geyer, 2015). RDoC domains such as cognitive control can be measured using the 5-Choice Continuous Performance Test (5C-CPT) (Lustig et al, 2013; Young et al, 2009, 2013a), in which patients with schizophrenia (Young et al, 2013a) and bipolar mania (Young, Geyer, Minassian and Perry; unpublished observations) exhibit deficits. Positive valence, specifically the subconstruct of preference-based decision making of approach motivation, can be measured using a probabilistic learning task (Amitai et al, 2013; Bari et al, 2010), in which schizophrenia patients exhibit deficits (Armstrong et al, 2012; Gold et al, 2008; Ragland et al, 2012a; Waltz et al, 2011). The subconstruct of effort valuation can be measured using the progressive ratio breakpoint paradigm (PRBP; Bensadoun et al, 2004; Young and Geyer, 2010,) that is also impaired in schizophrenia patients (Ellenbroek and Cools, 2000; Wolf et al, 2014). Hence, in the current studies, we examined the cognitive control and aspects of approach motivation of Sp4 Hyp mice and their wild-type (WT) littermates in these paradigms. Given the reduced NMDAR function in these mice, we also tested whether a glycine type-1 transporter (GlyT-1) inhibitor could remediate any deficits observed, as glycine is a NMDAR co-agonist (Javitt, 2012; Javitt et al, 2001).

\section{MATERIALS AND METHODS}

\section{Animals}

For all behavioral experiments, the same cohort of male Sp4 WT $(n=17)$ and Hyp $(n=11)$ mice were generated from heterozygous breeding pairs. The Sp4 mice were generated as previously described (Zhou et al, 2005) and maintained as Sp4 heterozygous in 129S mice and Black Swiss backgrounds. In brief, a nuclear $L a c Z$ expression cassette was capped with a splicing acceptor and further flanked by two loxP sites. The floxed LacZ cassette was inserted into the first intron of mouse $S p 4$ gene, and followed by a rat $S p 4 \mathrm{cDNA}$ gene fused in frame into the second exon of mouse Sp4 gene (Zhou et al, 2005). Mouse endogenous Sp4 gene was replaced by the targeting cassette via homologous recombination. Expression of the rat $S p 4$ gene was blocked by the upstream $L a c Z$ gene tagged with three transcription terminators. Because of leakage of transcription termination in vivo, there is $2-5 \%$ of the level of Sp4 expression in Sp4 homozygous mice compared with WT mice. These Sp4 mutant mice were therefore termed Sp4 Hyp mice. After breeding the Sp4 Hyp mice with Cre lines, the LacZ gene can be deleted by the Cre to restore Sp4 gene expression. All test mice were the F1 generation mice with the same genetic background (Ji et al,
2013; Zhou et al, 2010), were 3 months old at the time of testing, and weighed between 21 and $28 \mathrm{~g}$. All animals were group housed (maximum four/cage) and maintained in a temperature-controlled vivarium $\left(21 \pm 1^{\circ} \mathrm{C}\right)$ with a reversed $12 \mathrm{~h}$ day/night cycle (lights off at $0700 \mathrm{~h}$ and on at $1900 \mathrm{~h}$ ). During training, mice were food restricted to maintain weight at $85 \%$ of their free-feeding weight, as is commonly used during reward-learning training (Young et al, 2011). For quantification of GlyT-1 levels, 8 WT and 7 Hyp mice at 5 months were used (see Supplementary Methods). Water was available ad libitum except during training and testing that occurred during the dark phase of the day/night cycle between 0800 and $1200 \mathrm{~h}$. All behavioral testing procedures were approved by the UCSD Animal Care and Use Committee before initiation of experiments. The UCSD animal facility meets all federal and state requirements for animal care.

\section{Drugs}

Org 24598 lithium salt and d-amphetamine were purchased from Sigma Aldrich (St Louis, MO) and dissolved in saline. Based on previous reports (Achat-Mendes et al, 2012; Lido et al, 2012), Org $24598(0.3,1$, and $3 \mathrm{mg} / \mathrm{kg})$ was injected intraperitoneally with a volume of $5 \mathrm{ml} / \mathrm{kg}, 30 \mathrm{~min}$ before testing. d-amphetamine $(1 \mathrm{mg} / \mathrm{kg})$ was injected intraperitoneally with a volume of $5 \mathrm{ml} / \mathrm{kg}, 5 \mathrm{~min}$ before testing, based on evidence of improvement in probabilistic learning (Young, Khan and Powell; unpublished observations). Freebase drug weight was used in all drug calculations.

\section{Apparatus}

5-Choice chambers. Training and testing took place in four 5 -hole operant chambers $(25 \times 25 \times 25 \mathrm{~cm}$; Med Associates, St Albans, VT) consisting of an array of five square holes $(2.5 \times 2.5 \times 2.5 \mathrm{~cm})$ arranged horizontally on a curved wall $2.5 \mathrm{~cm}$ above the grid floor (Figure 1a) as described elsewhere (van Enkhuizen et al, 2013). This array was opposite a food delivery magazine (Lafayette Instruments, Lafayette, IN) located at floor level with a house light located near the ceiling. The chamber was located in a soundattenuating box, ventilated by a fan that also provided a low level of background noise. An infrared camera installed in each chamber enabled the monitoring of performance during training and testing. Mice were trained to respond with a nose-poke to an illuminated LED recessed into the holes. Responses were detected by infrared beams mounted vertically and located $3 \mathrm{~mm}$ from the opening of the hole. Liquid reinforcement in the form of strawberry milkshake (Nesquik plus nonfat milk, $30 \mu \mathrm{l}$ ) was delivered by peristaltic pump (Lafayette Instruments) to a well located in the magazine opposite the 5-hole wall. Magazine entries were monitored using an infrared beam mounted horizontally $5 \mathrm{~mm}$ from the floor and recessed $6 \mathrm{~mm}$ into the magazine. The control of stimuli and recording of responses were managed by a SmartCtrl Package 8-In/16-Out with additional interfacing by MED-PC for Windows (Med Associates) using custom programming (Amitai et al, 2013; Young et al, 2012, 2013c).

Progressive ratio breakpoint testing. Mice were trained in the 5-choice serial reaction-time task daily, 5 days per week, 


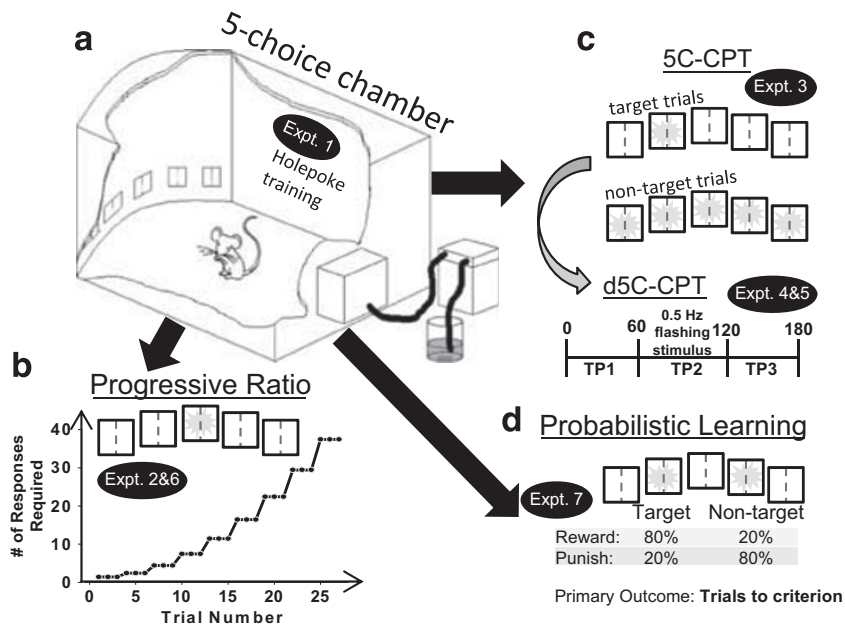

Figure I Behavioral challenges on Sp4 hypomorphic and wild-type mice. (a) Sp4 mutant mice were trained to respond to lit holes in 5-choice chambers whereby a response in any one of the five recessed apertures (detected by infrared beams, vertical dashed line) resulted in strawberry milkshake reward delivery. (b) After initial training mice were tested in the progressive ratio breakpoint schedule of reinforcement. Because the number of responses required in the central aperture for a single reward kept increasing after three 3 responses/rewards at that level, this challenge established the motivation of mice to work for a single reward. The 'breakpoint' of the mice indicated their willingness to work for a single reward. (c) Mice were then trained on the 5-choice continuous performance test (5C-CPT) that required mice to differentiate between target and nontarget trials, requiring responding in the singly lit aperture or inhibiting when all five apertures were lit respectively. Mice were then challenged in the distracting (d)5C-CPT where during trial periods I and 3 (trials $\mathrm{I}-60$ and $|2|-\mid 80$ ) the task was consistent with the standard 5CCPT, but during trial period 2 (trials $6 \mathrm{I}-120$ ) a $0.5 \mathrm{~Hz}$ flashing light continuously occurred. (d) After these studies, mice were challenged in the probabilistic learning paradigm, wherein mice were presented with a right or left stimulus. One stimulus was assigned as target and the other as nontarget, with responses to the former rewarded (milkshake) $80 \%$ and punished (4 s illuminated house light) $20 \%$ of the time and vice-versa for the latter.

as described previously (Young and Geyer, 2010,). Each session lasted $30 \mathrm{~min}$ or 120 trials, whichever was completed first. Training began by associating the magazine delivering reward in conjunction with its illumination (Hab1). Mice were then trained to respond into any one of the five apertures for a single reward (Hab2). Once responding reliably ( $>70$ responses in $30 \mathrm{~min}$ for 2 consecutive days), mice were challenged in the breakpoint study. The number of nose-pokes required to gain a reward increased according to the following progression: $1,2,4,7,11,16,22,29,37,46$, 56 , and 67. To maintain responding, each ratio had three steps before moving to the next ratio (Figure 1b). Importantly, for each completed step, mice only received one reward. The session continued for $60 \mathrm{~min}$ or until $5 \mathrm{~min}$ had passed without a nose poke. The breakpoint was defined as the last ratio to be completed before the session ended. Mean reward latencies (MRLs) and mean response latencies were also calculated. The progressive ratio challenge was conducted on Tuesday with normal shaping on the previous day.

5-Choice continuous performance test training. After PRBP testing, mice were retrained in $\mathrm{Hab} 2$ requiring responses in all apertures (Wednesday-Friday). The mice were then moved onto $5 \mathrm{C}$-CPT training as previously described (Young et al, 2009, 2013c). Each trial was initiated by the mouse nose-poking and then removing its nose from the magazine. After a 5-s ITI, a light stimulus appeared in one of the five apertures located opposite the magazine. A nose-poke in the lit aperture during the stimulus duration (SD) plus a 2-s limited hold period resulted in a correct (Hit) response being registered and a reward being delivered in the magazine. A nose-poke in any other aperture over this period was registered as an incorrect response and resulted in a 4-s time-out (TO). Failure to respond in any aperture during the SD+limited hold was registered as an omission (omission+incorrect $=$ Miss) and also resulted in a TO. Response in any aperture during the ITI registered a premature response and triggered a TO. The next trial began when the mouse entered and then exited the magazine. The SD started at $20 \mathrm{~s}$ and was reduced to 10,8 , and $4 \mathrm{~s}$ after the attainment of each criterion (a mean correct latency less than half the current SD for 2 consecutive days) across sessions. At this point, mice were transferred to a variable ITI (3-7 s). Once performance stabilized ( $\sim 1$ week), the mice were transferred to the $5 \mathrm{C}$-CPT. For the $5 \mathrm{C}$-CPT, 100 trials were target trials, identical to trials described in the 5-choice serial reaction-time task where a cue stimulus could appear in any 1 of the 5 apertures, 20 trials were nontarget trials, unique to the $5 \mathrm{C}$-CPT in which all 5 apertures were illuminated, and the mouse was required to inhibit responding (Figure 1c). Training took $\sim 4$ months. Consistent with human CPTs (Riccio et al, 2002), successful inhibition of a response in a nontarget trial resulted in a correct rejection $(C R)$ being recorded and reward delivered. Responding in a nontarget trial, however, resulted in a false alarm $(F A)$ being registered and a TO occurring. These nontarget trials were interspersed pseudorandomly within the 100 target trials (maximum of 3 sequential no-go trials). For all 3 tasks, the mean correct latency (MCL) was calculated along with the following parameters:

Measures resulting from target trials only

$$
\begin{aligned}
\text { accuracy } & =\frac{\text { Hit }}{\text { Hit }+ \text { Incorrect }} \% \text { Omissions } \\
& =\left(\frac{\text { omissions }}{\text { TotalTrials }}\right) \times 100 \\
p(H R)= & \frac{\text { Hit }}{H i t+\text { Miss }}
\end{aligned}
$$

Measures resulting from target and nontarget trials

$p(F A)=\frac{F A}{F A+C R}$

Based upon these basic parameters, signal detection indices (Green and Swets, 1966; McNicol, 1972) were calculated to assess both sensitivity index (SI) and responsivity index bias (RI). The SI was calculated using the following formula:

$$
S I=\frac{p(H R)-p(F A)}{2[p(H R)+p(F A)]-[p(H R)+p(F A)]^{2}}
$$

SI provides a nonparametric assessment of sensitivity (Frey and Colliver, 1973). Values for SI vary from -1 to +1 , with 
+1 indicating that all target events were responded to, whereas all nontarget events were inhibited from responding to, and 0 indicating chance levels of distinguishing between signal and nonsignal events. SI was also the basis by which McGaughy and Sarter (1995) developed their vigilance index measure and hence would produce comparable results for mice to those seen in rats performing their vigilance paradigm. To mirror the use of SI, the nonparametric response bias measure RI (Frey and Colliver, 1973) was chosen to provide a measure of the 'tendency to respond' (Frey and Colliver, 1973; Marston, 1996; Sahgal, 1987).

$R I=\frac{p(H R)+p(F A)-1}{1-[p(F A)-p(H R)]^{2}}$

Both SI and RI are based on the same geometric logic and are both appropriate for use with single choice procedures (respond or not; Marston, 1996).

Probabilistic learning assessment. This task was based on a similar task developed by Bari et al (2010) and previously described (Amitai et al, 2013). Briefly, the task presented two stimuli (holes 2 and 4) wherein responses by mice in one aperture (target) were reward $80 \%$ and punished $20 \%$ of the time, whereas the contingencies were reversed for responses in the other aperture (nontarget; Figure 1d). This session lasted $1 \mathrm{~h}$, and learning criterion performance was defined as eight consecutive nose-poke responses (rewarded or unrewarded) into the target location. The apertures were illuminated until a response was made. The primary outcome measure was trials to criterion. Secondary measures included a measurements of motor impulsivity-premature responses-and strategy formation analysis-including target win-stay ratio (no. of target responses after rewarded target response/ no. of total responses after rewarded target response), nontarget win-stay ratio (no. of nontarget responses after rewarded nontarget response/no. of total responses after rewarded nontarget response), target lose-shift ratio (no. of nontarget responses after punished target response/no. of total responses after punished target response), and nontarget lose-shift ratio (no. of target responses after punished nontarget response/no. of total responses after punished nontarget response).

\section{Experimental Challenges}

Once trained to respond in lit apertures (experiment 1), the Sp4 mice were tested in the progressive ratio breakpoint procedure (experiment 2) in order to gauge the motivation of mice to work for a single reward (Barnes et al, 2014; Markou et al, 2013), as described previously (Bensadoun et al, 2004; Young and Geyer, 2010,). The mice were then trained in the $5 \mathrm{C}-\mathrm{CPT}$ and stable baseline performance recorded (experiment 3). The cognitive control of mice was then challenged on a single test day (Wednesday) between normal training sessions (Monday, Tuesday, Thursday, and Friday) using the distracting (d)5C-CPT (Figure 1c). This challenge mirrored work by Sarter and colleagues (Demeter et al, 2013; Howe et al, 2010), designed to further measure control of attention (Lustig et al, 2013). The test session was split into 3 blocks of 60 trials wherein the second (middle) block included a flashing light during trials, located $2 \mathrm{~cm}$ above the array and flashing at $0.5 \mathrm{~Hz}$ (experiment 4). This challenge was then used to test the effects of GlyT-1 inhibition on performance. Mice were treated with Org 24598 before testing in the d5C-CPT (experiment 5). Mice were then retested in the progressive ratio breakpoint challenge with Org 24598 treatment at $1 \mathrm{mg} / \mathrm{kg}$ before testing (experiment 6). The mice were then tested in the within-session probabilistic learning paradigm to assess the effects of Org 24598 or amphetamine on the learning of these mice (experiment 7). Finally, assessment of GlyT-1 levels in a new cohort of mice was established (experiment 8).

\section{Statistics}

Acquisition of hole-poking in the 5-choice chambers was analyzed by comparing the number of days to criterion for $\mathrm{Hab} 1$ ( $>30$ reward associations for 2 consecutive days) and $\mathrm{Hab} 2$ ( $>70$ responses for 2 consecutive days) between the two genotypes using independent samples $t$-tests. Baseline 5C-CPT data were analyzed using a two-way repeated measures ANOVA with day as a within-subjects factor and genotype as the between-subjects factor. The distraction challenge data were analyzed using a two-way repeated measures ANOVA with trial period as a within-subjects factor and genotype as a between-subjects factor. When tested with the GlyT-1 inhibitor, drug dose was also included as a within-subjects factor. To assess motivation, mice were tested in the progressive ratio breakpoint study using an independent $t$-test to compare measures between genotypes. When tested with the GlyT-1 inhibitor, data were analyzed using two-way ANOVAs with genotype as a betweensubjects factor and drug as a within-subjects factor. For the probabilistic learning study, data were analyzed using two separate two-way ANOVAs with the GlyT-1 inhibition and amphetamine data were analyzed separately as withinsubject factors and genotype as the between-subjects factor. GlyT-1 levels were compared across genotypes using a twotailed $t$-test. All data were analyzed using SPSS (20.0, Chicago, IL).

\section{RESULTS}

\section{Experiment 1: Response Acquisition Training}

Sp4 Hyp mice took longer to acquire both the association between food delivery and illumination $\left(t_{(26)}=-5.7\right.$, $p<0.0001)$ and hole response for reward $\left(t_{(26)}=-4.1\right.$, $p<0.0001$; see Table 1$)$. When trained to hole-poke in a single lit cue for a reward, Sp4 Hyp took significantly longer to acquire the task than WT littermates $\left(t_{(26)}=-2.4\right.$, $p<0.05)$.

\section{Experiment 2: Sp4 Mutant Effects on Progressive Ratio Breakpoint Schedule of Reinforcement}

Once responding stably, the mice were challenged with a PRBP to assess motivation. Overall, Sp4 Hyp mice tended to have a lower breakpoint $\left(\mathrm{F}_{(1,25)}=3.6, p<0.1\right.$; Supplementary Figure 1A) and exhibited a significantly slower mean response time $\left(\mathrm{F}_{(1,25)}=12.8, p<0.005\right.$; Supplementary Figure $1 \mathrm{~B}$ ) compared with WT mice. However, latencies to 
Table I Comparison of Operant Training between Sp4 Wild-Type (WT) and Hypomorphic (Hyp) Mice

\begin{tabular}{lccc}
\hline Sp4 & $\begin{array}{c}\text { Magazine illumination/ } \\
\text { reward delivery acquisition (HAB I) }\end{array}$ & $\begin{array}{c}\text { 5-Hole array } \\
\text { responding (HAB2) }\end{array}$ & $\begin{array}{c}\text { Single lit hole } \\
\text { choice acquisition }\end{array}$ \\
\hline WT & $3.1( \pm 0.1)$ & $6.5( \pm 0.4)$ & $18.0( \pm 2.1)$ \\
Hyp & $5.1( \pm 0.4)^{*}$ & $20.9( \pm 4.3)^{*}$ & $25.8( \pm 4.1) *$ \\
\hline
\end{tabular}

Data presented as mean \pm SEM.

*P $<0.05$ cf. WT.

collect rewards did not differ between the two genotypes $(\mathrm{F}<1$, NS; Supplementary Figure $1 \mathrm{C})$.

\section{Experiment 3: 5C-CPT: Baseline Performance}

Once trained, the stability of 5C-CPT performance of Sp4 mutant mice was assessed across 4 days. Sp4 Hyp mice exhibited poorer vigilance compared with WT mice $\left(\mathrm{F}_{(1,22)}=3.8, p<0.05\right.$; Supplementary Figure $\left.2 \mathrm{~A}\right)$. In oneway $t$-test analyses, WT mice exhibited higher vigilance than chance responding $\left(t_{(15)}=3.5, p<0.005\right)$, whereas Sp4 mice did not $\left(t_{(13)}=1.0\right.$, NS). This deficit was driven by a lower Hit Rate $\left(\mathrm{F}_{(1,22)}=12.5, p<0.001\right.$; Supplementary Figure $\left.2 \mathrm{~B}\right)$ compared with WT mice, as the False Alarm Rate was unchanged $(\mathrm{F}<1$, NS; Supplementary Figure 2C). Sp4 Hyp mice were also less responsive than $\mathrm{WT}$ mice $\left(\mathrm{F}_{(1,22)}=4.5\right.$, $p<0.05$; Supplementary Figure 2D), as measured using the RI. However, no genotype effect was observed in the total number of trials $(\mathrm{F}<1, \mathrm{NS})$. Sp4 Hyp mice were also less accurate in responding than $\mathrm{WT}$ mice $\left(\mathrm{F}_{(1,22)}=6.3, p<0.05\right.$; Supplementary Figure 2E). The lower Hit Rate of Sp4 Hyp mice was driven by a higher $\%$ omissions than WT mice $\left(\mathrm{F}_{(1,22)}=10.7, p<0.001\right.$; Supplementary Figure $\left.2 \mathrm{~F}\right)$. The Sp4 Hyp mice were also slower to correctly respond compared with WT mice $\left(\mathrm{F}_{(1,22)}=16.7, p<0.005\right.$; Supplementary Figure $2 \mathrm{G})$. No genotypic difference in premature responses was observed ( $\mathrm{F}<1$, NS; Supplementary Figure $2 \mathrm{G}$ ). Stability of performance was demonstrated by a lack of improvement in any of these measures over days as well as a lack of interaction with genotype $(\mathrm{F}<1.6$, NS; Supplementary Figure $2 \mathrm{H}$ ).

\section{Experiment 4: 5C-CPT: Effects of Within-Session Distraction}

After identifying poor vigilance of Sp4 mutant mice, we then assessed their control of attention using a visual distracting paradigm. During trials $41-80$, a distracting visual stimulus located above the stimulus array flashed at $0.5 \mathrm{~Hz}$ (Figure 2i). A main trial-period effect $\left(\mathrm{F}_{(2,50)}=5.9, p<0.001\right.$; Figure 2a) revealed that vigilance performance was worst during the distracting trial period compared with the first and third trial periods $(p<0.05)$. No genotype $\times$ trial-period interaction was observed $(\mathrm{F}<1, \mathrm{NS})$, revealing that Sp4 Hyp mice tended to perform worse $\left(\mathrm{F}_{(2,32)}=3.7, p=0.067\right)$ than $\mathrm{WT}$ mice throughout the session.

Overall, no effect of Trial Period, genotype, or their interaction was observed for Hit Rate $(\mathrm{F}<2.4$, NS; Figure $2 \mathrm{~b}$ ) or False Alarm Rate $(\mathrm{F}<1, \mathrm{NS}$; Figure $2 \mathrm{c})$. However, Trial Period tended to affect response bias as measured by RI $\left(\mathrm{F}_{(2,50)}=3.1, p=0.063\right.$; Figure $\left.2 \mathrm{~d}\right)$, indicating that mice in trial period 3 (after distraction) were more responsive compared with the other two trial periods $(p<0.05)$. No effect of Trial Period, genotype, or their interaction was observed for Accuracy $(\mathrm{F}<2.0, \mathrm{NS}$; Figure 2e). The $\%$ omissions of mice were lower in trial period 3 after distraction $\left(\mathrm{F}_{(2,50)}=6.6, p<0.005\right.$; Figure $\left.2 \mathrm{f}\right)$ compared with trial periods 1 and $2(p<0.05)$. No effect of genotype or interaction with Trial Period was observed $(\mathrm{F}<2.5$, NS). A main effect of Trial Period was observed in premature responses $\left(\mathrm{F}_{(2,50)}=12.3, p<0.001\right.$; Figure $\left.2 \mathrm{~g}\right)$, driven by higher levels during the distracting period compared with the other two trial periods $(p<0.001)$. No effect of genotype or its interaction with Trial Period was observed $(\mathrm{F}<1$, NS). Finally, mice exhibited faster reaction times $\left(\mathrm{F}_{(2,50)}=4.2\right.$, $p<0.05$; Figure $2 \mathrm{~h}$ ) in trial periods 2 and 3 (during and after distraction) compared with the first trial period $(p<0.05)$.

\section{Experiment 5: GlyT-1 Inhibitory Effects on 5C-CPT of SP4 Mutant Mice during Distraction}

Unlike baseline performance, Sp4 mice did not exhibit lower $d^{\prime}$ levels overall $\left(\mathrm{F}_{(1,16)}=2.0\right.$, NS), likely as a result of genotype $\times$ GlyT-1 inhibition interaction $\left(\mathrm{F}_{(2,32)}=4.9\right.$, $p<0.05$; Figure 3$)$. The post hoc ANOVA analyses revealed that GlyT-1 inhibition tended to lower $d^{\prime}$ in WT mice $\left(\mathrm{F}_{(2,22)}=2.7, p=0.092\right)$, but significantly increased it in Sp4 Hyp mice $\left(\mathrm{F}_{(2,10)}=3.2, p<0.05\right)$. These effects were irrespective of trial period and hence were unlikely to be attributable to treatment effects on distraction. Although no overall effect of trial period was observed $\left(\mathrm{F}_{(2,32)}=2.1\right.$, NS), performance was significantly lower during distraction compared with trial period $3(p<0.05)$.

During this challenge, Sp4 Hyp mice had a comparable Hit Rate with WT mice $(\mathrm{F}<1, \mathrm{NS})$. Moreover, genotype did not interact with trial period, drug treatment, or both $(\mathrm{F}<1.6$, $\mathrm{NS})$. However, a trial period $\times$ drug treatment interaction was observed $\left(\mathrm{F}_{(4,64)}=5.0, p<0.005\right)$. The post hoc analyses revealed that Hit Rate during the distracting trial period was significantly lower $\left(\mathrm{F}_{(2,32)}=3.6, p<0.05\right)$ than the other two periods $(p<0.05)$ in mice treated with saline. Interestingly, a main trial period effect was also seen in mice treated with $0.3 \mathrm{mg} / \mathrm{kg}$ of the GlyT-1 inhibitor $\left(\mathrm{F}_{(2,32)}=6.5, p<0.005\right)$ but this effect was driven by poor performance in the final trial period after the distracting trial period. No main effect of trial period was seen in mice treated with $1 \mathrm{mg} / \mathrm{kg}$ of the GlyT-1 inhibitor $\left(\mathrm{F}_{(2,32)}=2.2, \mathrm{NS}\right)$, although performance was worst during the distracting trial period. In terms of response disinhibition measured by false alarms, no effect of any factor or their interaction was observed $(\mathrm{F}<1.1, \mathrm{NS})$. Neither genotype nor Trial Period nor GlyT-1 inhibition 

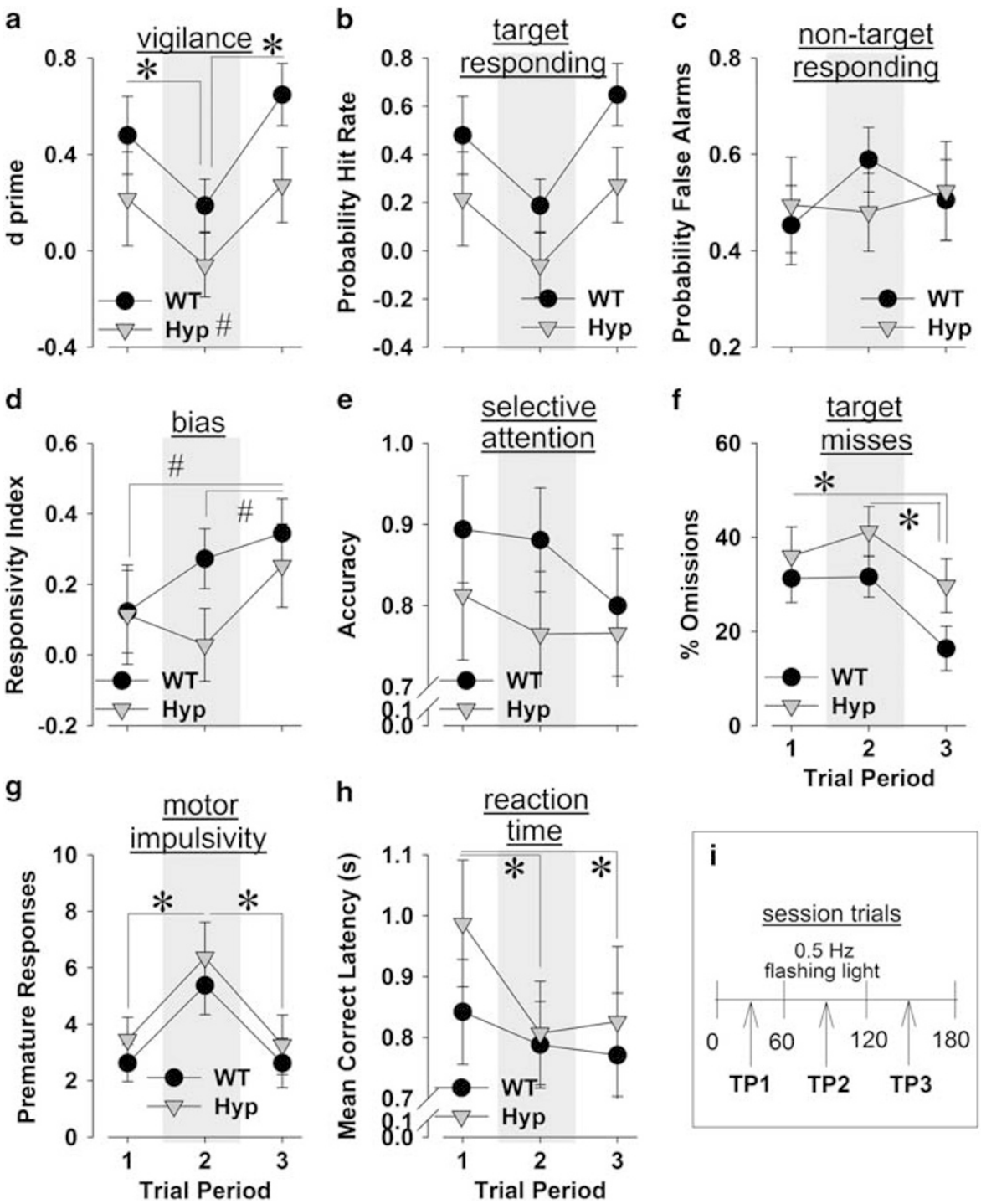

Figure 2 Effect of distraction on the control of attention of Sp4 hypomorphic (Hyp) and wild-type (WT) littermate mice. After baseline assessment, the control of attention of Sp4 Hyp and WT littermate mice was assessed by flashing $0.5 \mathrm{~Hz}$ light stimulus during the middle trial period of testing (shaded section). The vigilance performance of both WT and Hyp mice was deleteriously affected by distraction, with Sp4 Hyp tending to exhibit poorer performance irrespective of Trial Period (a). Responses to targets were primarily, though nonsignificantly, affected by the distracting stimulus (b) as response inhibition was unaffected (c). Interestingly, mice were responding more liberally after the distraction irrespective of genotype (d). The selective attention (accuracy) of mice was unaffected by the distracting stimulus (e), whereas target misses were reduced after distraction ( $f$ ). Mice were more motorically impulsive during the distracting Trial Period (g), whereas reaction times (latency to respond) were also sped during and after distraction irrespective of genotypes (h). The breakdown of distracting vs nondistracting trial period is depicted (i). Data presented as mean \pm SEM, $* P<0.05$, ${ }^{\#} p<0$. I compared with indicated direction.

affected or interacted together to affect response bias measured using the RI $(\mathrm{F}<2.1, \mathrm{NS})$.

Sp4 Hyp mice did not differ in accuracy $(\mathrm{F}<1.9$, NS) compared with WT mice during this challenge. No effect of Trial Period, drug, or the interaction with any of these factors was observed $(\mathrm{F}<2.0, \mathrm{NS})$. GlyT-1 inhibition affected \% omissions $\left(\mathrm{F}_{(2,32)}=3.4, p<0.05\right)$, although this effect was driven by differences in mice receiving 1.0 vs $0.3 \mathrm{mg} / \mathrm{kg}$ $(p<0.05)$. No main effect or interaction with any other factor was observed $(\mathrm{F}<2.0, \mathrm{NS})$. The main effects of trial period $\left(\mathrm{F}_{(2,32)}=9.3, p<0.005\right)$ and a GlyT- $1 \times$ trial period interaction $\left(\mathrm{F}_{(4,64)}=4.1, \quad p<0.01\right)$ were observed for motor impulsivity measured by premature responses. No genotype or any other interaction was observed $(\mathrm{F}<1.8, \mathrm{NS})$. During distraction, there was a significant increase in premature responses compared with the other trial periods $(p<0.05)$. Higher motor impulsivity during distraction was seen in mice treated with saline $\left(\mathrm{F}_{(2,32)}=9.5, p<0.001\right)$ and $0.3 \mathrm{mg} / \mathrm{kg}$ GlyT-1 inhibitor $\left(\mathrm{F}_{(2,32)}=8.1, p<0.001\right)$, but not at $1.0 \mathrm{mg} / \mathrm{kg}(\mathrm{F}<1, \mathrm{NS})$, compared with the other two trial periods $(p<0.05)$. Higher premature responses in mice receiving $1 \mathrm{mg} / \mathrm{kg}$ of the GlyT-1 inhibitor $\left(\mathrm{F}_{(2,32)}=3.7\right.$, $p<0.05)$ compared with saline $(p<0.05)$ were observed during trial period 3 but not at any other trial period. GlyT-1 inhibition affected mean reaction time $\left(\mathrm{F}_{(2,32)}=3.8, p<0.05\right)$ without interacting or main effect of any other factor $(\mathrm{F}<1.2, \mathrm{NS})$. Finally, the reaction time of mice given $1 \mathrm{mg} / \mathrm{kg}$ GlyT-1 inhibitor was slower than those given $0.3 \mathrm{mg} / \mathrm{kg}$ 
$(p<0.05)$ and tended to be slower than those receiving saline $(p<0.1)$.

\section{Experiment 6: GlyT-1 Inhibitory Effects on Breakpoint in Sp4 Mutant Mice}

Sp4 Hyp mice exhibited a lower breakpoint than WT mice $\left(\mathrm{F}_{(1,16)}=9.0, p<0.05\right.$; Figure 4a). GlyT-1 inhibition did not affect the breakpoint of mice or interact with genotype

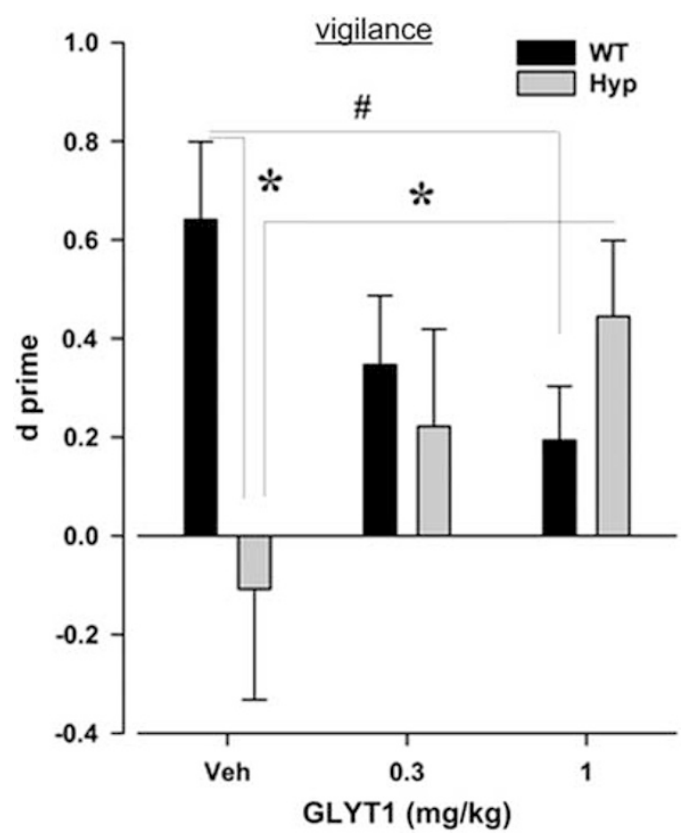

Figure 3 GlyT-I inhibition-induced changes in vigilance of Sp4 hypomorphic (Hyp) and wild-type (WT) littermate mice. GlyT-I inhibition using Org 24598 significantly improved the vigilance of Sp4 Hyp mice as measured by $d^{\prime}$ measured over the entire session. However, GLYTI inhibition tended to deleteriously affect the vigilance of WT littermate mice. Data presented as mean+SEM, ${ }^{*} P<0.05,{ }^{\#} p<0.1$ compared with indicated control.
( $\mathrm{F}<1$, NS). Sp4 Hyp mice collected rewards as fast as WT mice $\left(F_{(1,16)}=2.0\right.$, NS; Figure $\left.4 b\right)$, which was slowed by GlyT-1 inhibition in both genotypes $\left(\mathrm{F}_{(1,16)}=10.5, p<0.01\right)$, as exhibited by a lack of interaction of the two factors $(\mathrm{F}<1, \mathrm{NS})$. Interestingly, GlyT-1 inhibition did not affect response latency, nor was there an effect of, or interaction with, genotype $(\mathrm{F}<1.4$, NS; Figure $4 \mathrm{c})$.

\section{Experiment 7: GlyT-1 Inhibitory Effects on Probabilistic Learning in Sp4 Mutant Mice}

Sp4 Hyp mice required more trials to attain criterion compared with WT mice $\left(\mathrm{F}_{(1,14)}=7.6, p<0.05\right.$; Figure 5a). However, GLYT-1 inhibition did not affect this learning $\left(\mathrm{F}_{(3,42)}=1.9\right.$, NS), neither in WT nor Hyp mice as exhibited by a lack of drug and genotype interaction $(\mathrm{F}<1$, NS). Importantly, the positive control (amphetamine treatment) tended to improve trials to criterion performance compared with saline treatment $\left(\mathrm{F}_{(1,14)}=3.6, p=0.077\right)$ irrespective of genotype $\left(F_{(1,14)}=2.4\right.$, NS). This trend for an amphetamineinduced improvement is consistent with previous findings that were significant with a larger sample size (data not shown).

GlyT-1 inhibition, amphetamine, genotype, or their interactions did not affect premature responding $(\mathrm{F}<1, \mathrm{NS}$; Figure 5b). GlyT-1 inhibition $\left(\mathrm{F}_{(3,42)}=3.4, p<0.05\right)$ and genotype $\left(\mathrm{F}_{(1,14)}=11.2, p<0.01\right)$ affected target win-stay behavior without interacting $(\mathrm{F}<1, \mathrm{NS}$; Figure $5 \mathrm{c})$. The post hoc analyses revealed that the middle dose increased target win-stay choices compared with saline $(p<0.05)$, whereas Sp4 Hyp mice had lower overall target win-stay choices than WT mice $(p<0.05)$. Interestingly, the middle dose resulted in the lowest trials to criterion, although not significantly different from vehicle (see above). In terms of shifting after punishment, GlyT-1 inhibition did not affect, nor interact with genotype, target lose-shift behavior $(\mathrm{F}<1.2, \mathrm{NS})$, although Sp4 Hyp mice tended to have lower shift levels after punishment from the target than WT mice $\left(\mathrm{F}_{(1,14)}=4.2\right.$,
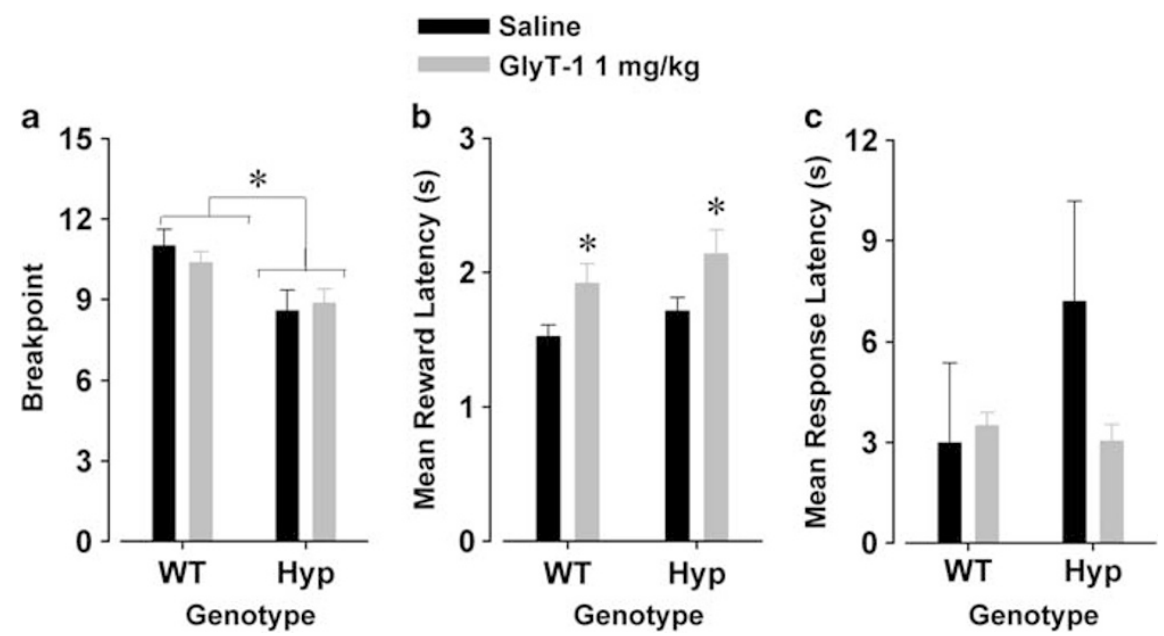

Figure 4 GlyT-I inhibition did not alter poor motivation of Sp4 hypomorphic (Hyp) or wild-type (WT) littermate mice. Consistent with baseline testing, Sp4 Hyp mice exhibited a reduced breakpoint compared with WT littermates (a). During this testing period, Hyp mice also exhibited a slower latency to collect rewards (b), but no changes in latency to respond (c). None of these behaviors were affected by GlyT-I inhibition via acute Org 24598 treatment. Data presented as mean+SEM, $* P<0.05$ compared with indicated group or saline. 

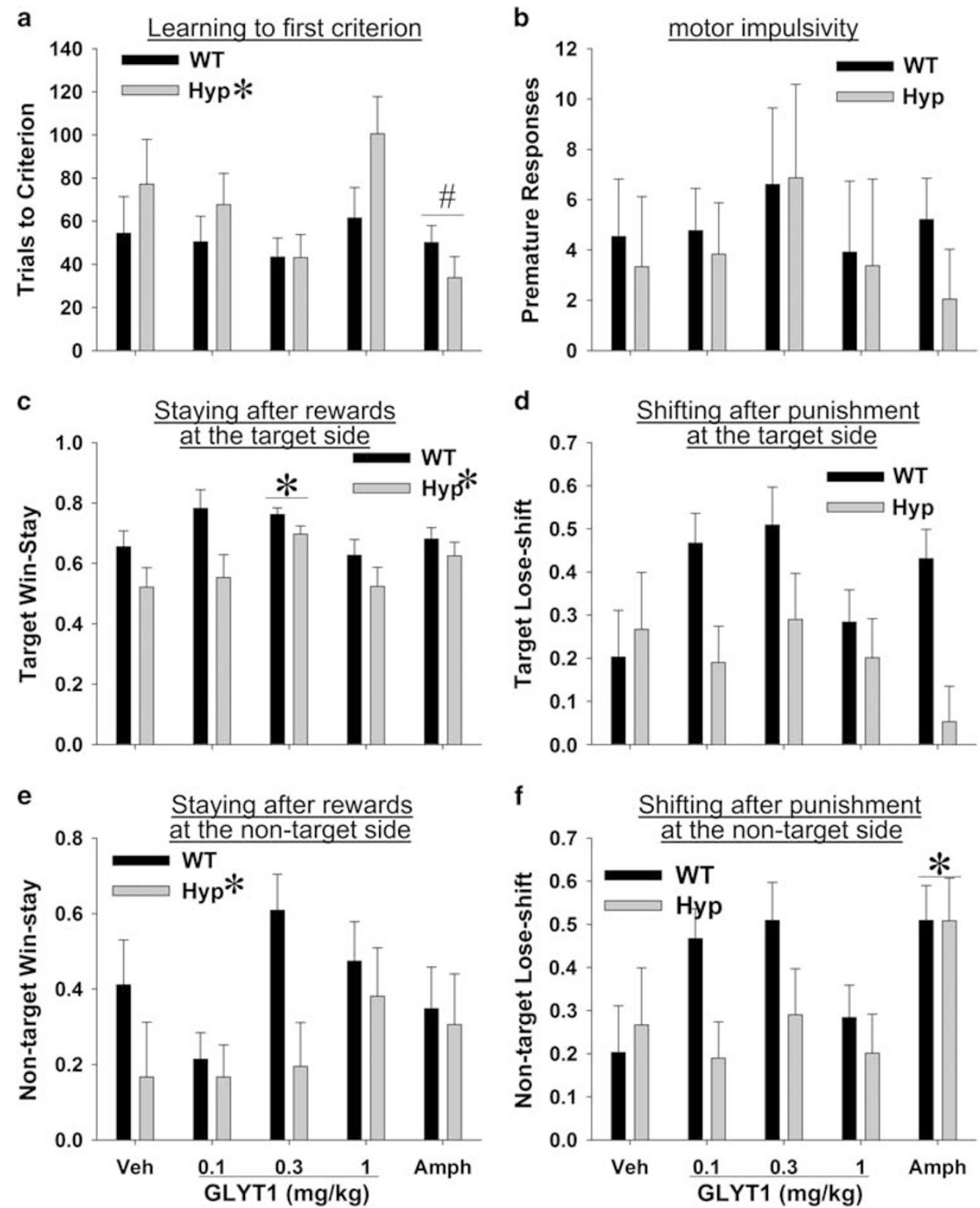

Figure 5 GlyT-I inhibition did not alter poor reward-associative learning of Sp4 hypomorphic (Hyp) or wild-type (WT) littermate mice. Sp4 Hyp mice exhibited poorer probabilistic reward-associative learning compared with WT littermate mice as measured by trials to criterion (a). Although partial remediation was seen at $0.3 \mathrm{mg} / \mathrm{kg}$ of GlyT-I inhibition treatment by Org 24598, this effect did not reach statistical significant. Amphetamine treatment tended to improve learning of both Sp4 WT and Hyp mice. Motor impulsivity as measured by premature responses was not affected by genotype, GlyT-I inhibition, or amphetamine treatment (b). Impaired probabilistic learning of Sp4 Hyp mice was likely driven by lower target win-stay, reflecting that WT mice were more likely to stay at the target side compared with Hyp mice (c). GlyT-I inhibition at $0.3 \mathrm{mg} / \mathrm{kg}$ improved target win-stay in both genotypes. Shifting after a punishment on the target side was unaffected by any treatment (d). Sp4 Hyp mice were also less likely to stay at the nontarget side after being rewarded, with neither GlyTI inhibition nor amphetamine treatment affecting this behavior (e). Amphetamine treatment improved probabilistic learning primarily by increasing the likelihood of the animal to shift after being punished on the nontarget stimulus ( $\mathrm{f}$ ). Data presented as mean $+\mathrm{SEM}$, *P $<0.05$ compared with indicated control (genotype or saline), ${ }^{\#} p<0.1$ compared with saline.

$p=0.061$; Figure 5d). GlyT-1 inhibition did not significantly affect nontarget win-stay $\left(\mathrm{F}_{(3,42)}=2.2\right.$, NS; Figure $\left.5 \mathrm{e}\right)$, whereas Sp4 mice exhibited lower nontarget win-stay behavior than WT $\left(\mathrm{F}_{(1,14)}=5.2, p<0.05\right)$, again with no interaction between these two factors. Finally, neither GlyT-1 inhibition $(\mathrm{F}<1, \mathrm{NS})$ nor genotype $\left(\mathrm{F}_{(1,14)}=2.4\right.$, NS; Figure 5f) nor their interaction $(\mathrm{F}<1.4, \mathrm{NS})$ affected nontarget lose-shifting behavior. Amphetamine did not exert any main effects on any of these measures $(\mathrm{F}<1.6, \mathrm{NS})$ except for nontarget lose-shift $\left(\mathrm{F}_{(3,42)}=5.7, p<0.05\right)$, wherein it elevated lose-shift in WT and Hyp mice compared with saline $(p<0.05)$.

\section{Experiment 8: Comparable GlyT-1 Levels in Sp4 WT and Hyp Mice}

The GlyT-1 levels of Sp4 WT and Hyp mice were measured and compared. GlyT-1 levels did not differ by genotype 
$\left(t_{(13)}=1.3, p=0.215\right)$. Hence, the differential effect of GlyT-1 inhibition was likely a result of altered downstream mechanism(s) from this inhibition (Supplementary Figure 3).

\section{DISCUSSION}

Sp4 Hyp mice exhibited impaired cognitive control, poor reward-associative learning, reduced effort to gain rewards, and low positive valence. This pattern of results is highly consistent with profiles of deficits observed in schizophrenia patients using similar tasks. Hence, reduced Sp4 expression during neurodevelopment results in a behavioral profile that is consistent with cognitive and negative symptoms of schizophrenia. Moreover, by using this model organism relevant to schizophrenia, we demonstrated that GlyT-1 inhibition (Org 24598) significantly reversed the attentional but not learning or motivational deficits of these mice. Interestingly, GlyT-1 inhibition impaired the attention of WT littermate mice without affecting their learning or motivation (summarized in Table 2). These data support GlyT-1 inhibition as a potential treatment for attentional but not positive valence deficiencies (negative symptoms) related to schizophrenia as well as a U-shape dose response of optimal synaptic glycine levels for attentional performance.

Sp4 Hyp mice exhibit impaired attentional performance at baseline in the 5C-CPT (Supplementary Figure 2A and Figure $2 \mathrm{a}$ ) consistent with the impaired attention of chronic sufferers with schizophrenia in the human 5C-CPT (Young et al, 2013a). However, some subtle differences between Sp4 mice and patients exist in specific 5C-CPT performance measures, including impaired accuracy and a significantly more conservative response bias in these mice (Supplementary Figure 2D and E), although the direction of effect for these measures was the same in patients as in Sp4 Hyp mice (Young et al, 2013a). Another notable difference is that Sp4 mice exhibited only chance levels of responding (Supplementary Figure 2A), suggesting they may exhibit difficulties in differentiating between target and nontarget stimuli. However, when treated with the GlyT-1 inhibitor, performance increased significantly above chance levels (Figure 3). Combined with unaltered GlyT-1 levels in Sp4 Hyp mice (Supplementary Figure 3), these findings support a putative NMDAR mediation of attentional deficits in Hyp mice related to their reduced NMDAR protein expression (Zhou et al, 2010). Importantly, increasing glycine levels demonstrated that the Sp4 Hyp mice knew how to perform the task, enabling them to perform at similar levels to WT mice. In contrast however, GlyT-1 inhibition worsened the 5C-CPT performance of WT mice at the same doses. These data support recent findings of a U-shaped optimal glycine level required for attentional maintenance during a delaydependent memory task in non-human primates (Castner et al, 2014). Hence, optimizing glycine levels using a GlyT-1 inhibitor may be a useful treatment for patients with schizophrenia with impaired attentional functioning as measured by the 5C-CPT.

Although GlyT-1 inhibition clearly affected overall attentional functioning in a manner consistent with previous findings and hypothesized models, it did not interact with attentional performance while under distraction using the 5C-CPT challenge. This challenge was based on work by Sarter and colleagues (Demeter et al, 2013; Howe et al, 2010) demonstrating that competing flashing stimuli during attentional performance deleteriously affected attentional performance. As reported for humans and rats (Demeter et al, 2013; Howe et al, 2010), we demonstrated that the attentional performance of mice was deleteriously affected by distracting stimuli (trial period 2, cf. trial periods 1 and 3; Figure $2 \mathrm{a}$ and $\mathrm{i}$ ). Distraction did not affect simple accuracy of responding but increased premature responding (Figure $2 \mathrm{e}$ and g). Interestingly, Sp4 Hyp mice were as distracted as WT mice as measured by $d^{\prime}$. This finding is consistent with the report that healthy subjects and patients with schizophrenia exhibit similar reductions in performance during distraction in the dSAT (Demeter et al, 2013). Thus, despite the reported importance of deficits in attentional control (in response to distraction) in schizophrenia patients (Luck et al, 2011; Lustig et al, 2013), perhaps general attention/vigilance remains primarily important to improve outcome for patients with schizophrenia. The Sp4 Hyp mice may prove a valid model organism-and GlyT-1 inhibition a viable therapeutic target-for impaired attention seen in patients with schizophrenia (Javitt, 2012).

In addition to impaired attention, Sp4 Hyp mice tended to exhibit a reduced breakpoint in the progressive ratio task (Supplementary Figure 1A) that was confirmed as significant upon retesting (Figure 4a). Reduced breakpoint in a progressive ratio setting has often been suggested as a measure of reduced motivation in mice that is relevant to negative symptoms in schizophrenia (Barnes et al, 2014; Ellenbroek and Cools, 2000; Markou et al, 2013; Young et al, 2010). Support for these assertions comes from recent evidence of reduced breakpoint in patients with schizophrenia that negatively correlated with negative symptom scale ratings (Wolf et al, 2014). One could theorize that this reduced breakpoint stems from lower NMDAR expression in these mice, but this deficit was not remediated by GlyT-1 inhibition (Figure 4a), unlike that seen for attention (Figure 3). Considering the importance of $\mathrm{Sp} 4$ expression during neurodevelopment (Ramos et al, 2007; Zhou et al, 2007),

Table 2 Summary of Cognitive/Motivational Profile of Sp4 Hypomorphic (Hyp) Compared with Wild-Type (WT) Mice

\begin{tabular}{|c|c|c|c|}
\hline Paradigm & Domain measured & Sp4 Hyp effect? & GlyT I inhibition effect? \\
\hline 5-Choice continuous performance test & Control of attention, inhibition & Impaired: driven by inattention & Attenuated deficit, impaired WT mice \\
\hline Probabilistic learning & $\begin{array}{l}\text { Feedback-driven learning/decision } \\
\text { making }\end{array}$ & $\begin{array}{l}\text { Impaired: driven by poor reward } \\
\text { learning }\end{array}$ & $\begin{array}{l}\text { No effect, but improved with } \\
\text { amphetamine }\end{array}$ \\
\hline Progressive ratio Breakpoint study & Effortful motivation & Impaired: driven by reduced effort & No effect \\
\hline
\end{tabular}


the mechanism(s) underlying this amotivation of Sp4 Hyp mice remain unclear.

Consistent with evidence of reduced motivation to work for a reward, the Sp4 Hyp mice also exhibited impaired probabilistic learning compared with their WT littermates (Figure 5a). This deficit was driven by a reduced likelihood of staying at the target side after being rewarded at that sidehence reduced reward sensitivity (Figure 5c). These findings support the premise that these mice exhibit impaired anticipation of reward. Such impaired probabilistic (rewardassociative) learning has also been linked to anhedonia and negative symptoms in schizophrenia (Dowd and Barch, 2010; Waltz and Gold, 2007), via impaired reward anticipation (Acheson et al, 2013; Gold et al, 2008). However, these deficits could still be linked to impaired cognition, given that probabilistic learning was suggested by the CNTRICS initiative to measure long-term relational memory (Armstrong et al, 2012; Ragland et al, 2012b). As with the progressive ratio challenge, GlyT-1 inhibition did not ameliorate the probabilistic learning deficits of Sp4 Hyp mice, although modest improvements were seen at $0.3 \mathrm{mg} /$ $\mathrm{kg}$. The LTP deficits of Sp4 Hyp mice may underlie their associative learning deficits. As GlyT-1 inhibition did not remediate their learning deficits but instead improved their attention, it is unlikely it would remediate their LTP deficits. However, improved probabilistic learning was observed in both WT and Sp4 mice treated with amphetamine (Figure 5). Hence, it appears that these negative symptom-relevant behavioral deficits can be attenuated by elevating dopamine and norepinephrine activity, but not glycine levels. Because amphetamine can enhance LTP (Xu et al, 2010), it is possible that it would also improve the LTP of Sp4 Hyp mice, as will be assessed in future studies. Considering however that probabilistic learning of both Sp4 WT and Hyp mice was improved by amphetamine treatment, this finding may not specifically reveal the mechanism(s) underlying the deficit of Sp4 Hyp mice.

Taken together, the inability of GlyT1-inhibition to remediate behaviors relevant to negative symptoms is surprising given that: (1) lower plasma and cerebrospinal fluid glycine level of patients with schizophrenia is linked to negative symptoms (Hashimoto et al, 2003); and (2) glycine treatment (although chronic) modestly lowers negative symptom ratings (Heresco-Levy et al, 1999; Javitt et al, 1994). However, such positive findings have not always been reproduced (Buchanan et al, 2007). In fact, Roche recently stopped trials testing a GlyT-1 inhibitor for the improvement of negative symptoms in schizophrenia, perhaps due in part to the sole reliance on clinical rating scales rather than objective translational laboratory tests as primary outcome measures. Testing negative symptoms using laboratory-based measures with relevance to those presented here may provide more relevant cross-species findings (Barnes et al, 2014; Der-Avakian et al, 2013; Young et al, 2013b) and greater sensitivity to the effects of GlyT-1 inhibitors. Constitutively reducing Sp4 expression in mice resulted in impaired attention that was remediated by GlyT-1 inhibition. The finding that this treatment did not remediate motivational deficits suggests that the attentional deficits of Sp4 mice are unlikely a result of altered motivation or learning. The lack of effect on motivation could be because of a requirement of longer treatment duration, although it improved attention acutely. Alternatively, more direct NMDAR1 activation may be required. Furthermore, the mechanism(s) underlying impaired motivation and learning resulting from reduced $\mathrm{Sp} 4$ expression have yet to be delineated. As SP4 regulates the transcription of NMDA receptor subunits GluN1, GluN2A, and GluN2B (Priya et al, 2014; Priya et al, 2013), further investigation of other mechanisms using these mice is warranted.

In conclusion, reduced $\mathrm{Sp} 4$ expression in mice largely recreates the attentional deficits observed in patients with schizophrenia as measured by the 5C-CPT (Young et al, 2013a). These data support pairing attentional assessment with evidence of reduced SP4 levels in peripheral blood mononuclear cells, as seen in first-episode patients with schizophrenia (Fuste et al, 2013). Such an approach might provide a useful personalized biomarker for predicting whether GlyT-1 inhibition may remediate attentional deficits in individual patients. However, such treatment would unlikely treat impaired positive valence related to reward anticipation. SP4 rare copy number variations and reduced protein levels are linked to several psychiatric disorders that exhibit attentional deficits including schizophrenia, bipolar disorder, and major depressive disorder (Pinacho et al, 2011; Shi et al, 2011; Tam et al, 2010; Zhou et al, 2009). Hence, identifying the mechanism(s) of how reducing Sp4 levels negatively affect attention and the neurobiology underlying GlyT-1 inhibition-induced reversal of these effects will prove vital. Importantly though, the present work using this model organism provides opportunities for personalized medicine for the treatment of attentional deficits in neuropsychiatric patients having low SP4 levels (McMahon and Insel, 2012).

\section{FUNDING AND DISCLOSURE}

Ms Mary Kamenski and Dr Zhou declare no conflict of interest. GL has served as a consultant for Astellas, Forum Pharmaceuticals, Boehringer Ingelheim, and Neuroverse. In the past 3 years, Dr Geyer has received consulting compensation from Abbott, Dart, Lundbeck, Neurocrine, Omeros, Otsuka, and Sunovion, and holds an equity interest in San Diego Instruments. Dr Geyer also has research grant support from NIDA, NIMH, and the US Veteran's Administration VISN 22 Mental Illness Research, Education, and Clinical Center. In the past 3 years, Dr Young's work has been funded by NIDA and NIMH, as well as the US Veteran's Administration VISN 22 Mental Illness, Research, Education, and Clinical Center, Cerca Insights, Lundbeck, and Omeros, and has received consulting compensation for Amgen. Company funding support did not provide any role in the design, collection or analysis of studies..

\section{ACKNOWLEDGMENTS}

We thank Richard Sharp and Mahálah Buell for their support. Specifically, these studies were supported by NIH grants R01-MH073991, R01-MH104344, and R21MH101579, as well as by the Brain and Behavior Research Foundation and by pilot funding from the UCSD Clinical Translational Research Initiative. 


\section{REFERENCES}

Achat-Mendes C, Nic Dhonnchadha BA, Platt DM, Kantak KM, Spealman RD (2012). Glycine transporter-1 inhibition preceding extinction training inhibits reacquisition of cocaine seeking. Neuropsychopharmacology 37: 2837-2845.

Acheson DT, Twamley EW, Young JW (2013). Reward learning as a potential target for pharmacological augmentation of cognitive remediation for schizophrenia: a roadmap for preclinical development. Front Neurosci 7: 103.

Amitai N, Young JW, Higa K, Sharp RF, Geyer MA, Powell SB (2013). Isolation rearing effects on probabilistic learning and cognitive flexibility in rats. Cogn Affect Behav Neurosci 14: 388-406.

Armstrong K, Williams LE, Heckers S (2012). Revised associative inference paradigm confirms relational memory impairment in schizophrenia. Neuropsychology 26: 451-458.

Bari A, Theobald DE, Caprioli D, Mar AC, Aidoo-Micah A, Dalley JW et al (2010). Serotonin modulates sensitivity to reward and negative feedback in a probabilistic reversal learning task in rats. Neuropsychopharmacology 35: 1290-1301.

Barnes SA, Der-Avakian A, Markou A (2014). Anhedonia, avolition, and anticipatory deficits: assessments in animals with relevance to the negative symptoms of schizophrenia. Eur Neuropsychopharmacol 24: 744-758.

Bensadoun JC, Brooks SP, Dunnett SB (2004). Free operant and discrete trial performance of mice in the nine-hole box apparatus: validation using amphetamine and scopolamine. Psychopharmacology (Berl) 174: 396-405.

Buchanan RW, Javitt DC, Marder SR, Schooler NR, Gold JM, McMahon RP et al (2007). The Cognitive and Negative Symptoms in Schizophrenia Trial (CONSIST): the efficacy of glutamatergic agents for negative symptoms and cognitive impairments. Am J Psychiatry 164: 1593-1602.

Castner SA, Murthy NV, Ridler K, Herdon H, Roberts BM, Weinzimmer DP et al (2014). Relationship between glycine transporter 1 inhibition as measured with positron emission tomography and changes in cognitive performances in nonhuman primates. Neuropsychopharmacology 39: 2742-2749.

Cuthbert BN (2014). The RDoC framework: facilitating transition from ICD/DSM to dimensional approaches that integrate neuroscience and psychopathology. World Psychiatry 13: 28-35.

Demeter E, Guthrie SK, Taylor SF, Sarter M, Lustig C (2013). Increased distractor vulnerability but preserved vigilance in patients with schizophrenia: evidence from a translational Sustained Attention Task. Schizophr Res 144: 136-141.

Der-Avakian A, D'Souza MS, Pizzagalli DA, Markou A (2013). Assessment of reward responsiveness in the response bias probabilistic reward task in rats: implications for cross-species translational research. Transl Psychiatry 3: e297.

Dowd EC, Barch DM (2010). Anhedonia and emotional experience in schizophrenia: neural and behavioral indicators. Biol Psychiatry 67: 902-911.

Ellenbroek BA, Cools AR (2000). Animal models for the negative symptoms of schizophrenia. Behav Pharmacol 11: 223-233.

Frey PW, Colliver JA (1973). Sensitivity and responsibility measures for discrimination learning. Learn Motiv 4: 327-342.

Fuste M, Pinacho R, Melendez-Perez I, Villalmanzo N, Villalta-Gil V, Haro JM et al (2013). Reduced expression of SP1 and SP4 transcription factors in peripheral blood mononuclear cells in firstepisode psychosis. J Psychiatr Res 47: 1608-1614.

Gold JM, Waltz JA, Prentice KJ, Morris SE, Heerey EA (2008). Reward processing in schizophrenia: a deficit in the representation of value. Schizophr Bull 34: 835-847.

Green DM, Swets JA (1966). Signal Detection Theory and Psychophysics. Wiley \& Sons: New YorkNew York.

Hashimoto K, Fukushima T, Shimizu E, Komatsu N, Watanabe H, Shinoda $\mathrm{N}$ et al (2003). Decreased serum levels of D-serine in patients with schizophrenia: evidence in support of the N-methyl$\mathrm{D}$-aspartate receptor hypofunction hypothesis of schizophrenia. Arch Gen Psychiatry 60: 572-576.

Heresco-Levy U, Javitt DC, Ermilov M, Mordel C, Silipo G, Lichtenstein M (1999). Efficacy of high-dose glycine in the treatment of enduring negative symptoms of schizophrenia. Arch Gen Psychiatry 56: 29-36.

Howe WM, Ji J, Parikh V, Williams S, Mocaer E, Trocme-Thibierge C et al (2010). Enhancement of attentional performance by selective stimulation of alpha4beta2 $\left(^{*}\right)$ nAChRs: underlying cholinergic mechanisms. Neuropsychopharmacology 35: 1391-1401.

Insel TR, Wang PS (2010). Rethinking mental illness. JAMA 303: 1970-1971.

Javitt DC (2012). Glycine transport inhibitors in the treatment of schizophrenia. Handb Exp Pharmacol 367-399.

Javitt DC, Silipo G, Cienfuegos A, Shelley AM, Bark N, Park M et al (2001). Adjunctive high-dose glycine in the treatment of schizophrenia. Int J Neuropsychopharmacol 4: 385-391.

Javitt DC, Zylberman I, Zukin SR, Heresco-Levy U, Lindenmayer JP (1994). Amelioration of negative symptoms in schizophrenia by glycine. Am J Psychiatry 151: 1234-1236.

Ji B, Wang X, Pinto-Duarte A, Kim M, Caldwell S, Young JW et al (2013). Prolonged ketamine effects in hypomorphic mice: mimicking phenotypes of schizophrenia. PLoS One 8: e66327.

Lido HH, Marston H, Ericson M, Soderpalm B (2012). The glycine reuptake inhibitor Org24598 and acamprosate reduce ethanol intake in the rat; tolerance development to acamprosate but not to Org24598. Addict Biol 17: 897-907.

Luby ED, Cohen BD, Rosenbaum G, Gottlieb JS, Kelley R (1959). Study of a new schizophrenomimetic drug; sernyl. AMA Arch Neurol Psychiatry 81: 363-369.

Luck SJ, Ford JM, Sarter M, Lustig C (2011). CNTRICS final biomarker selection: control of Attention. Schizophr Bull 38: 53-61.

Lustig C, Kozak R, Sarter M, Young JW, Robbins TW (2013). CNTRICS final animal model task selection: control of attention. Neurosci Biobehav Rev 37: 2099-2110.

Markou A, Salamone JD, Bussey TJ, Mar AC, Brunner D, Gilmour $\mathrm{G}$ et al (2013). Measuring reinforcement learning and motivation constructs in experimental animals: relevance to the negative symptoms of schizophrenia. Neurosci Biobehav Rev 37: 2149-2165.

Marston HM (1996). Analysis of cognitive function in animals, the value of SDT. Brain Res Cogn Brain Res 3: 269-277.

McGaughy J, Sarter M (1995). Behavioral vigilance in rats: task validation and effects of age, amphetamine, and benzodiazepine receptor ligands. Psychopharmacology (Berl) 117: 340-357.

McMahon FJ, Insel TR (2012). Pharmacogenomics and personalized medicine in neuropsychiatry. Neuron 74: 773-776.

McNicol D (1972). A Primer of Signal Detection Theory. George Allen \& Unwin: LondonLondon.

Perry W, Minassian A, Paulus MP, Young JW, Kincaid MJ, Ferguson EJ et al (2009). A reverse-translational study of dysfunctional exploration in psychiatric disorders: from mice to men. Arch Gen Psychiatry 66: 1072-1080.

Pinacho R, Villalmanzo N, Lalonde J, Haro JM, Meana JJ, Gill G et al (2011). The transcription factor SP4 is reduced in postmortem cerebellum of bipolar disorder subjects: control by depolarization and lithium. Bipolar Disord 13: 474-485.

Priya A, Johar K, Nair B, Wong-Riley MT (2014). Specificity protein 4 (Sp4) regulates the transcription of AMPA receptor subunit GluA2 (Gria2). Biochim Biophys Acta 1843: 1196-1206.

Priya A, Johar K, Wong-Riley MT (2013). Specificity protein 4 functionally regulates the transcription of NMDA receptor subunits GluN1, GluN2A, and GluN2B. Biochim Biophys Acta 1833: 2745-2756. 
Ragland JD, Blumenfeld RS, Ramsay IS, Yonelinas A, Yoon J, Solomon $\mathrm{M}$ et al (2012a). Neural correlates of relational and itemspecific encoding during working and long-term memory in schizophrenia. Neuroimage 59: 1719-1726.

Ragland JD, Cohen NJ, Cools R, Frank MJ, Hannula DE, Ranganath C (2012b). CNTRICS imaging biomarkers final task selection: Long-term memory and reinforcement learning. Schizophr Bull 38: 62-72.

Ramos B, Gaudilliere B, Bonni A, Gill G (2007). Transcription factor Sp4 regulates dendritic patterning during cerebellar maturation. Proc Natl Acad Sci U S A 104: 9882-9887.

Riccio CA, Reynolds CR, Lowe P, Moore JJ (2002). The continuous performance test: a window on the neural substrates for attention? Arch Clin Neuropsychol 17: 235-272.

Sahgal A (1987). Some limitations of indices derived from signal detection theory: evaluation of an alternative index for measuring bias in memory tasks. Psychopharmacology (Berl) 91: 517-520.

Shi J, Potash JB, Knowles JA, Weissman MM, Coryell W, Scheftner WA et al (2011). Genome-wide association study of recurrent early-onset major depressive disorder. Mol Psychiatry 16: 193-201.

Sun X, Pinacho R, Saia G, Punko D, Meana JJ, Ramos B et al (2014). Transcription factor Sp4 regulates expression of nervous wreck 2 to control NMDAR1 levels and dendrite patterning. Dev Neurobiol 75: 93-108.

Supp DM, Witte DP, Branford WW, Smith EP, Potter SS (1996). Sp4, a member of the Sp1-family of zinc finger transcription factors, is required for normal murine growth, viability, and male fertility. Dev Biol 176: 284-299.

Tam GW, van de Lagemaat LN, Redon R, Strathdee KE, Croning MD, Malloy MP et al (2010). Confirmed rare copy number variants implicate novel genes in schizophrenia. Biochem Soc Trans 38: 445-451.

van Enkhuizen J, Acheson D, Risbrough V, Drummond S, Geyer MA, Young JW (2013). Sleep deprivation impairs performance in the 5-choice continuous performance test: Similarities between humans and mice. Behav Brain Res 261C: 40-48.

Waltz JA, Frank MJ, Wiecki TV, Gold JM (2011). Altered probabilistic learning and response biases in schizophrenia: behavioral evidence and neurocomputational modeling. Neuropsychology 25: 86-97.

Waltz JA, Gold JM (2007). Probabilistic reversal learning impairments in schizophrenia: further evidence of orbitofrontal dysfunction. Schizophr Res 93: 296-303.

Wolf DH, Satterthwaite TD, Kantrowitz JJ, Katchmar N, Vandekar L, Elliott MA et al (2014). Amotivation in schizophrenia: integrated assessment with behavioral, clinical, and imaging measures. Schizophr Bull 40: 1328-1337.

Xu TX, Ma Q, Spealman RD, Yao WD (2010). Amphetamine modulation of long-term potentiation in the prefrontal cortex: dose dependency, monoaminergic contributions, and paradoxical rescue in hyperdopaminergic mutant. $J$ Neurochem 115: 1643-1654.

Young J, Geyer M (2015)). . Developing treatments for cognitive deficits in schizophrenia: the challenge of translation. J Psychopharmacol 29: 178-196.

Young J, Kamenski M, Geyer M (2012). Delayed 'eureka' of alpha 7 nicotinic acetylcholine receptor knockout mice in a probabilistic reversal learning paradigm. Schizophr Res 136: S361.

Young JW, Geyer MA (2010). Action of modafinil-increased motivation via the dopamine transporter inhibition and D1 receptors? Biol Psychiatry 67: 784-787.

Young JW, Geyer MA, Rissling AJ, Sharp RF, Eyler LT, Asgaard GL et al (2013a). Reverse translation of the rodent 5C-CPT reveals that the impaired attention of people with schizophrenia is similar to scopolamine-induced deficits in mice. Transl Psychiatry 3: e324

Young JW, Jentsch JD, Bussey TJ, Wallace TL, Hutcheson DM (2013b). Consideration of species differences in developing novel molecules as cognition enhancers. Neurosci Biobehav Rev 37: 2181-2193.

Young JW, Light GA, Marston HM, Sharp R, Geyer MA (2009). The 5-choice continuous performance test: evidence for a translational test of vigilance for mice. PLoS One 4: e4227.

Young JW, Meves JM, Geyer MA (2013c). Nicotinic agonistinduced improvement of vigilance in mice in the 5-choice continuous performance test. Behav Brain Res 240: 119-133.

Young JW, Meves JM, Tarantino IS, Caldwell S, Geyer MA (2011). Delayed procedural learning in alpha7-nicotinic acetylcholine receptor knockout mice. Genes Brain Behav 10: 720-733.

Young JW, Zhou X, Geyer MA (2010)Animal models of schizophrenia. In: Swerdlow NR (ed) Behavioral Neurobiology of Schiozphrenia and Its Treatment. Springer: BerlinBerlin pp. 391-433.

Zhou X, Long JM, Geyer MA, Masliah E, Kelsoe JR, Wynshaw-Boris A et al (2005). Reduced expression of the Sp4 gene in mice causes deficits in sensorimotor gating and memory associated with hippocampal vacuolization. Mol Psychiatry 10: 393-406.

Zhou X, Nie Z, Roberts A, Zhang D, Sebat J, Malhotra D et al (2010). Reduced NMDAR1 expression in the Sp4 hypomorphic mouse may contribute to endophenotypes of human psychiatric disorders. Hum Mol Genet 19: 3797-3805.

Zhou X, Qyang Y, Kelsoe JR, Masliah E, Geyer MA (2007). Impaired postnatal development of hippocampal dentate gyrus in Sp4 null mutant mice. Genes Brain Behav 6: 269-276.

Zhou X, Tang W, Greenwood TA, Guo S, He L, Geyer MA et al (2009). Transcription factor SP4 is a susceptibility gene for bipolar disorder. PLoS One 4: e5196.

Supplementary Information accompanies the paper on the Neuropsychopharmacology website (http://www.nature.com/npp) 